\title{
In silico Analysis of Quercetin and its Analogues Against Targeted Proteins
}

\author{
Anitha Sekar ${ }^{1}$, Ranjani Soundhararajan 1(D), Hemalatha Srinivasan 1,* (D) \\ 1 School of Life Sciences, B. S. Abdur Rahman Crescent Institute of Science and Technology, Vandalur, India \\ * Correspondence: hemalatha.sls@bsauniv.ac.in;
}

Scopus Author ID 56895829300

Received: 3.01.2021; Revised: 5.02.2021; Accepted: 8.02.2021; Published: 15.02.2021

\begin{abstract}
Quercetin is a flavonoid compound present in many plants such as onions, tomatoes, apples, green tea, flax seeds, etc. It possesses antioxidant and anti-inflammatory effects that help control inflammation, kill cancer cells, and prevent heart disease. Wide evidence reveals quercetin's antitumor property to inhibit various cancers like breast, lung, nasopharyngeal, kidney, colorectal, pancreatic, prostate, and ovarian cancer. In this study, quercetin was docked against proteins such as Apoptic protein (APAF-1, BAX, BCL-2), Heat shock protein, Cytochrome p45O, Actin, Tyrosine-protein kinase hck. From the Insilico research completed, we can infer that quercetin and the analogs show great efficacy in finding against cancer and can be used in cancer care. These findings will help us understand the quercetin's binding ability with proteins and know-how quercetin is involved in the anticancer, antioxidant role.
\end{abstract}

Keywords: quercetin; antitumor; antioxidant; Apoptic protein; flavonoid; cancer.

\section{Abbreviations:}

2-P 4H BC 4-one

5,7-D-4H-C-4-0ne

5,7,2-T 6,8-DMTflavone

BNPF

HSP
2-Phenyl-4H-Benzo(H)Chromen-4-One;

5,7-Dihydroxy-2-(3,4,5-TrihydroxyphenylL)-4H-Chromen-4-One;

5,7,2-Trihydroxy-6,8-Dimethoxyflavone;

Betanapthaflavone;

Heat Shock Protein.

(C) 2021 by the authors. This article is an open-access article distributed under the terms and conditions of the Creative Commons Attribution (CC BY) license (https://creativecommons.org/licenses/by/4.0/).

\section{Introduction}

Cancer is one of the world's leading widespread disease and major causes of death. WHO estimates that every year, cancer such as lung, stomach, liver, colon, and breast cancer results in people's fatality $[1,2]$. Worldwide, death due to cancer has increased. Both genetic and environmental factors play a major part in the progression of cancer [3]. Sunlight exposure, tobacco, smoking, x rays, gamma rays, asbestos, disease, fried meat, barbecue meat, obesity, lack of exercise, radiation, caffeine are the key reason why cancer has entered the human body [4]. Red meat such as beef, lamb, and pork has been classified as the highest risk agent for cancer by the International cancer research agency [5].

Flavonoids are found to have an abundance of anti-cancer properties. It was known that flavonoids could prevent cancer and can also cure the disease. Flavonoids are compounds extracted from plants, mostly secondary metabolites with very strong anti-cancer and antiinflammatory properties. Flavonoids and their similar analogs are most used in ovarian, breast, cervical, pancreatic, and prostate cancer treatment. Quercetin is a plant flavanol of polyphenols from the flavonoid group [6-13]. Quercetin is commonly found in fruits, vegetables, leaves, 
and seeds. Quercetin is present more commonly in red onions, plum, pepper, green tea, red wine, and citrus fruit. The red onion contains a high concentration of quercetin. The half-life of quercetin is about 1 to 2 hours, water-insoluble, and soluble in an aqueous alkaline solution [14].

Some work shows that quercetin is considered a very good candidate for medicinal purposes, and quercetin oral administration induces its near-complete metabolization in the prevention of cancer. Metabolites also maintain antioxidant properties [15, 16]. On cellular models, quercetin suggests an almost exhaustive explanation of the mechanisms that link quercetin to the oxidative cell balance and help control phases of the cell cycle $[8,9,17]$.

Quercetin in the meal is conjugated with glycoside. The bioavailability of quercetin derived from onions is primarily quercetin glucoside, compared to quercetin derived from apple, which contains quercetin rhamnoside quercetin galactoside [18]. Quercetin generally exploits mitochondria-based pathway to induce apoptosis. Quercetin is also observed in several types of cancers for arresting the cell cycle [19-21]. Quercetin is capable of directly binding to tubulin by which cell microtubules are depolymerized. Apoptosis by quercetin is based on intrinsic and caspase-based pathways. Endoplasmic reticulum stress is evoked by quercetin, leading to apoptosis in ovarian cancer based on the mitochondria pathway. It can induce autophagy, thereby preventing ovarian cancer progression. Quercetin has a p-STAT3 / Bcl-2 axis, which is a central key player in inducing ER stress, apoptosis, and autophagy [22, 23]. Also, quercetin has been able to induce autophagy, which has a protective function in cancer cells in ovaries [24]. Quercetin reduces the survival of metastatic ovarian cancer cells and causes apoptosis $[25,26]$.

Quercetin interacts with testosterone at higher concentrations. It's generally a key cytostatic mechanism as the concentration are higher for inhibiting cell growth. Quercetin is also said to increase testosterone level and decrease DHT in a rat model in a dose-dependent manner after an initial rise. Quercetin, along with finasteride, is used as a combination drug to decrease prostatic hyperplasia progression and reduce the adverse effects of the native drug [27].

ROS-mediated DNA damage is also decreased by quercetin. Quercetin's high concentrations are also recognized as a strong inducer of apoptosis [25]. Pro-inflammatory cytokines expression was reduced by quercetin while stimulating with the rhinovirus. Also, in rat's, quercetin was identified to decrease the viral load and enhance lung function in a mouse model of Chronic Obstructive Pulmonary Disease [28]. For cancer prevention, it is recommended that quercetin be given orally. It was shown that the onset of colorectal cancer was significantly reduced by a diet supplemented with 2 percent quercetin. Quercetin has a low systemic toxicity biological function, attracting researcher's attention[29, 30]. Despite wide documentation, no field test has been conducted to validate the results. The quercetin also resensitizes enzalutamide to in vitro and in vivo enzalutamide-resistant prostate cancer cells by inhibiting the androgen receptor splice variant [31-33]. Quercetin is a fat-soluble compound that improves the bioavailability of fatty foods. The bioavailability of the quercetin can be increased by Non-digestible fibers. Bioavailability will be greater when supplemented as a fundamental part of a meal [34]. The study's main objective is to understand the quercetin and it's analog's, binding potential with the proteins APAF-1, BAX, BCL, Heat Shock Protein, Cytochrome P 450, Actin, and Tyrosine Protein Kinase. To determine the antioxidant properties and anti-cancer properties of quercetin through molecular docking studies and understanding its protein-binding capacity to fight against cancer. 


\section{Materials and Methods}

\subsection{Tools and database used.}

Biovia discovery studio, Open babel, Pubchem, RCSPDB, Molinspiration, ADMETSAR, Autodock 4.2.6, and Pymol were used in this study [35, 36].

\subsection{Preparation of ligand and protein.}

2D structure of "QUERCETIN" was downloaded from the PubChem website https://pubchem.ncbi.nlm.nih.gov/_and the file was converted into PDBQT format by using "OPENBABEL", same is repeated for all the quercetins analogs.

3D structure of the protein was downloaded from Pdb (Protein Data Bank) website https://www.rcsb.org/ and repeat the same for six other proteins.

\subsection{Docking of Quercetin and analogs against the selected proteins.}

Biovia discovery studio was used to remove the ligand and water molecule from the protein and help us get the exact protein structure alone. Autodock software was used to read the molecule, adding the polar hydrogens and Kollman charges. Later, Grid box was created, and spacing Armstrong is set to " 1 ". X, Y, Z values were set appropriately to produce a perfect grid box. Once protein and ligand were docked, torsion was selected, and the output file was selected in PDBQT format in MGL tools. The output was visualized using pymol software, and validation was evaluated [37-41].

\subsection{Prediction of drug bioactivity score and ADMET analysis.}

Canonical smiles for quercetin and it's analogs were copied from PubChem https://pubchem.ncbi.nlm.nih.gov/_and pasted in the "molinspiration website . "calculate properties" are selected to find the molecular property. Canonical smiles for quercetin and it's analogs are copied from PubChem https://pubchem.ncbi.nlm.nih.gov/ and pasted in the ADMET SAR VERSION 1. "Predict" option were selected to find the ADMET property.

\section{Results and Discussion}

Computational analysis by molecular docking is an important tool in structural analysis and screening of hit compounds. With the help of a three-dimensional protein structure, the best ligand binding position is identified. Protein-ligand docking software's identifies the best ligand binding score based on scoring features that predict high dimensional space. It helps in lead optimization. It is used to identify the ligand molecules to inhibit the target compound by scrutinizing a large library of compounds [42].

Log $\mathrm{P}$ is a very important physical biomolecular property that affects a wide range of systems. It is used in combination with other important parameters; it allows the work to move forward in many pharmaceutical industries and assess the chemical compound's fate for ligand or a substance. Log P's prediction provides the best way to direct scientists and researchers to produce more successful work and development results. The best value range for log $\mathrm{p}$ is roughly $2 . \log \mathrm{P}>5$ shows the high metabolic turnover, low solubility, and low oral absorption levels. Luteolin was given the best $\log P$ value, "1.97” from the results we received [43].

A lower TPSA value implies more beneficial for a drug-likeness property. TPSA value is considered to be low for CNS pervade [44]. Flavone and betanapthoflavone have low TPSA 
values while comparing with another ligand. This shows Flavone and betanapthoflavone have better drug-likeness properties (table 1).

High human intestinal absorption denotes the ligand can be better absorbed in the intestinal tract through oral administration. Apigenin, Flavone, 2-Phenyl-4HBenzo(H)Chromen-4-One and Betanapthaflavone tends to have better absorption in the human intestine. Chrysin has the best value for the BBB penetration. Ligand with a low value for acute rat toxicity is more toxic than the higher value. Recoflavone has the highest value among all for acute rat toxicity.

Table 1. Molinspiration results.

\begin{tabular}{l|c|c|c|c|c|c|c|c} 
Compound Name & Log P & TPSA & n atoms & Molecular Weight & nON & nOHNH & nrotb & Volume \\
\hline Quercetin & 1.68 & 131.35 & 22 & 302.24 & 7 & 5 & 1 & 240.08 \\
\hline Apigenin & 2.46 & 90.89 & 20 & 270.24 & 5 & 3 & 1 & 224.05 \\
\hline Chrysin & 2.94 & 70.67 & 19 & 254.24 & 4 & 2 & 1 & 216.03 \\
\hline Hispidulin & 2.48 & 100.13 & 22 & 300.27 & 6 & 3 & 2 & 249.59 \\
\hline Luteolin & 1.97 & 111.12 & 21 & 286.24 & 6 & 4 & 1 & 232.07 \\
\hline Diosmetin & 2.28 & 100.13 & 22 & 300.27 & 6 & 3 & 2 & 249.59 \\
\hline Fisetin & 1.97 & 111.12 & 21 & 286.24 & 6 & 4 & 1 & 232.07 \\
\hline Kaempherol & 1.13 & 170.05 & 31 & 432.38 & 10 & 6 & 3 & 355.93 \\
\hline Flavone & 3.74 & 30.21 & 17 & 222.24 & 2 & 0 & 1 & 200 \\
\hline $\begin{array}{l}\text { 2-Phenyl-4H- } \\
\text { Benzo(H)Chromen-4-One }\end{array}$ & 4.39 & 50.44 & 22 & 288.3 & 3 & 1 & 1 & 252 \\
\hline $\begin{array}{l}\text { 5,7-Dihydroxy-2-(3,4,5- } \\
\text { TrihydroxyphenylL)-4H- } \\
\text { Chromen-4-One }\end{array}$ & 1.66 & 151.15 & 22 & 382.24 & 7 & 5 & 1 & 240.08 \\
\hline $\begin{array}{l}\text { 5,7,2-Trihydroxy-6,8- } \\
\text { Dimethoxyflavone }\end{array}$ & 2.9 & 109.36 & 24 & 330.29 & 7 & 3 & 3 & 275.14 \\
\hline Recoflavone & 2.65 & 104.45 & 28 & 386.36 & 8 & 1 & 7 & 329.42 \\
\hline Icaritin & 4.96 & 100.13 & 27 & 368.38 & 6 & 3 & 4 & 326.94 \\
\hline Betanapthaflavone & 4.9 & 30.21 & 21 & 272.3 & 2 & 0 & 1 & 243.99
\end{tabular}

ADMET applies to Absorption, Distribution, Metabolism, Excretion, and Toxicity. The estimation of the ADMET properties plays a significant role in the drug design cycle because in the clinical phases, these properties account for the failure of around 60 percent of all drugs [45]. Such parameters influence drug delivery's kinetics to tissues that affect the pharmacological property and the compound's efficacy as a drug. The study's compounds all have good pharmacodynamics and pharmacokinetics [46]. All compounds had said they would follow the five rules of the Lipinski. All the ligands are in the range for bioreactivity ratings. The ligands are said to be safe and effective, and their use may be considered their use in cancer treatment. From the ADMET results, we can suggest all the ligands tend to be non-carcinogens, non-AMES toxicity, and not readily biodegradable (table 2).

Table 2. ADMET SAR results.

\begin{tabular}{|c|c|c|c|c|c|c|c|c|c|}
\hline $\begin{array}{l}\text { Compound } \\
\text { Name }\end{array}$ & $\begin{array}{l}\text { Human } \\
\text { Intestinal } \\
\text { Absorption }\end{array}$ & $\begin{array}{l}\text { Blood- } \\
\text { Brain } \\
\text { Barrier }\end{array}$ & $\begin{array}{l}\text { CYP2C9 } \\
\text { inhibition }\end{array}$ & $\begin{array}{l}\text { CYP2C9 } \\
\text { substrate }\end{array}$ & $\begin{array}{l}\text { AMES } \\
\text { toxicity }\end{array}$ & Carcinogens & $\begin{array}{l}\text { Acute } \\
\text { Oral } \\
\text { Toxicity }\end{array}$ & $\begin{array}{l}\text { Rat } \\
\text { Acute } \\
\text { Toxicity }\end{array}$ & Biodegradation \\
\hline Quercetin & 0.965 & 0.5711 & 0.5823 & 0.7898 & 0.722 & 0.945 & 0.7348 & 3.02 & 0.8672 \\
\hline Apigenin & 1 & 0.8731 & 0.6033 & 0.7775 & 0.8906 & 0.9181 & 0.7012 & 2.6983 & 0.8384 \\
\hline Chrysin & 0.9887 & 0.6364 & 0.7746 & 0.7813 & 0.8906 & 0.9181 & 0.7012 & 2.6983 & 0.8384 \\
\hline Hispidulin & 0.9783 & 0.6382 & 0.756 & 0.7326 & 0.9133 & 0.9423 & 0.7362 & 2.7192 & 0.8952 \\
\hline Luteolin & 0.965 & 0.5711 & 0.5823 & 0.7898 & 0.722 & 0.945 & 0.7348 & 3.02 & 0.8672 \\
\hline Diosmetin & 0.9783 & 0.6382 & 0.756 & 0.7326 & 0.9133 & 0.9423 & 0.7362 & 2.7192 & 0.8952 \\
\hline Fisetin & 0.8041 & 0.8542 & 0.9071 & 0.7639 & 0.5118 & 0.9608 & 0.5971 & 2.4984 & 0.8339 \\
\hline Kaempherol & 0.9051 & 0.7568 & 0.8538 & 0.7557 & 0.9319 & 0.9461 & 0.5184 & 2.5458 & 0.9073 \\
\hline Flavone & 1 & 0.8481 & 0.781 & 0.8242 & 0.6389 & 0.9088 & 0.6178 & 2.4662 & 0.9488 \\
\hline $\begin{array}{l}\text { 2-P 4H BC } \\
\text { 4-one }\end{array}$ & 1 & 0.8731 & 0.6033 & 0.7775 & 0.8139 & 0.8991 & 0.6941 & 2.6768 & 0.8264 \\
\hline $\begin{array}{l}\text { 5,7-D- } 4 \mathrm{H}- \\
\text { C-4-One }\end{array}$ & 0.965 & 0.5711 & 0.5823 & 0.7898 & 0.722 & 0.945 & 0.7348 & 3.02 & 0.8672 \\
\hline
\end{tabular}




\begin{tabular}{|c|c|c|c|c|c|c|c|c|c|}
\hline $\begin{array}{l}\text { Compound } \\
\text { Name }\end{array}$ & $\begin{array}{l}\text { Human } \\
\text { Intestinal } \\
\text { Absorption }\end{array}$ & $\begin{array}{l}\text { Blood- } \\
\text { Brain } \\
\text { Barrier }\end{array}$ & $\begin{array}{l}\text { CYP2C9 } \\
\text { inhibition }\end{array}$ & $\begin{array}{l}\text { CYP2C9 } \\
\text { substrate }\end{array}$ & $\begin{array}{l}\text { AMES } \\
\text { toxicity }\end{array}$ & Carcinogens & $\begin{array}{l}\text { Acute } \\
\text { Oral } \\
\text { Toxicity }\end{array}$ & $\begin{array}{l}\text { Rat } \\
\text { Acute } \\
\text { Toxicity }\end{array}$ & Biodegradation \\
\hline $\begin{array}{l}5,7,2-\mathrm{T} \quad 6,8- \\
\text { DMTflavone }\end{array}$ & 0.9719 & 0.6742 & 0.6258 & 0.7717 & 0.9429 & 0.9336 & 0.592 & 2.9348 & 0.9329 \\
\hline Recoflavone & 0.925 & 0.5814 & 0.753 & 0.7854 & 0.8551 & 0.9089 & 0.5098 & 3.1563 & 0.8638 \\
\hline Icaritin & 0.9859 & 0.8712 & 0.87 & 0.7888 & 0.7957 & 0.9431 & 0.659 & 2.9476 & 0.9578 \\
\hline BNPF & 1 & 0.9641 & 0.5201 & 0.809 & 0.731 & 0.9114 & 0.511 & 2.8447 & 0.7247 \\
\hline
\end{tabular}

By considering the overall summary result of quercetin and its analogs with cytochrome P450 (Fig 1a) we could interpret that 2-Phenyl-4H-Benzo (H) Chromen-4-One have a stronger interaction with cytochrome $\mathrm{P} 450$ with a binding score of -13.3 than other compounds. This is followed by Betanapthaflavone, which has a binding affinity of -12.6. The weaker interaction with cytochrome P450 was observed with Recoflavone. The RMSD value of all the ligands is accepted range as all the ligands have an average RMSD value less than 2.5 Quercetin, Apigenin, Chrysin, Hispidulin, Fisetin, Luteolin, and Kaempherol have the binding score within the range of -10.0 to- 11.0 which is considered to be the average to moderate binding affinity. Flavone has a binding energy of -11 , which means it has good interaction with protein (table 3).

Table 3. Energy and RMSD values for Cytochrome P450 with ligands.

\begin{tabular}{|c|c|c|c|}
\hline Protein with ligand & Energy & RMSD. LB & RMSD.UB \\
\hline Cytochrome P 450 With Quercetin & -10.6 & 0.000 & 0.000 \\
\hline Cytochrome P 450 With Apigenin & -10.7 & 0.000 & 0.000 \\
\hline Cytochrome P 450 With chrysin & -10.9 & 0.000 & 0.000 \\
\hline Cytochrome P 450 With Hispidulin & -10.1 & 0.000 & 0.000 \\
\hline Cytochrome P 450 With Luteolin & -10.6 & 0.000 & 0.000 \\
\hline Cytochrome P 450 With Diosmetin & -10.5 & 0.931 & 1.679 \\
\hline Cytochrome P 450 With Fisetin & -10.4 & 0.884 & 1.591 \\
\hline Cytochrome P 450 With Kaempherol & -10.7 & 0.000 & 0.000 \\
\hline Cytochrome P 450 With Flavone & -11.2 & 0.000 & 0.000 \\
\hline Cytochrome P 450 With 2-Phenyl-4H-Benzo(H)Chromen-4-One & -13.3 & 0.000 & 0.000 \\
\hline $\begin{array}{l}\text { Cytochrome P } \quad 450 \text { With 5,7-Dihydroxy-2-(3,4,5-TrihydroxyphenylL)-4H- } \\
\text { Chromen-4-One }\end{array}$ & -10.3 & 0.028 & 1.774 \\
\hline Cytochrome P 450 With 5,7,2-Trihydroxy-6,8-Dimethoxyflavone & -9.7 & 0.000 & 0.000 \\
\hline Cytochrome P 450 With Recoflavone & -9.0 & 0.000 & 0.000 \\
\hline Cytochrome P 450 With Icaritin & -9.7 & 0.000 & 0.000 \\
\hline Cytochrome P 450 With Betanapthaflavone & -12.6 & 0.000 & 0.000 \\
\hline
\end{tabular}

In the case of actin (Fig 1b), betanapthaflavone of $-9.5 \mathrm{kcal} / \mathrm{mol}$ has good interaction with the protein. Quercetin is said to possess weaker interaction with actin with a binding score of -6.0. All other compounds have an energy value above -6.0 , which can be considered moderate to average interaction with actin. Furthermore, the presence of hydrogen bonds also determines the binding affinity. The ligand-binding sites will be further studied. The RMSD value of quercetin and analogs are below -2.5 (table 4).

For Heat Shock Protein, the binding energy of 2-Phenyl-4H-Benzo (H) Chromen-4One (Fig 1c), and Recoflavone (Fig 1d) have a maximum binding energy of -7.3. These two compounds have a stronger interaction with HSP. Whereas the other compounds have a score in the range of -6.0. 5, 7, 2-Trihydroxy-6, 8- Dimethoxyflavone and Flavone have the least binding energy than other compounds; hence they are said to possess weak interaction with HSP. The RMSD value and druggability of all the ligands are satisfactory (table 5).

Table 4. Energy and RMSD values for actin with ligands.

\begin{tabular}{l|l|l|l} 
Protein with ligand & Energy & RMSD.LB & RMSD.UB \\
\hline Actin with Quercetin & -6.0 & 0.000 & 0.000 \\
\hline Actin with Apigenin & -7.6 & 1.338 & 2.200 \\
\hline Actin with chrysin & -8.8 & 0.000 & 0.000
\end{tabular}




\begin{tabular}{l|l|l|l} 
Protein with ligand & Energy & RMSD.LB & RMSD.UB \\
\hline Actin with Hispidulin & -9.1 & 0.000 & 0.000 \\
\hline Actin with Luteolin & -8.7 & 0.000 & 0.000 \\
\hline Actin with Diosmetin & -8.9 & 0.000 & 0.000 \\
\hline Actin with Fisetin & -7.7 & 0.000 & 0.000 \\
\hline Actin with Kaempherol & -7.7 & 0.000 & 0.000 \\
\hline Actin with Flavone & -7.6 & 1.008 & 1.771 \\
\hline Actin with 2-Phenyl-4H-Benzo(H)Chromen-4-One & -8.1 & 0.000 & 0.000 \\
\hline Actin with 5,7-Dihydroxy-2-(3,4,5-TrihydroxyphenylL)-4H-Chromen-4-One & -8.6 & 0.000 & 0.000 \\
\hline Actin with 5,7,2-Trihydroxy-6,8-Dimethoxyflavone & -7.4 & 0.000 & 0.000 \\
\hline Actin with Recoflavone & -7.3 & 0.000 & 0.000 \\
\hline Actin with Icaritin & -7.8 & 0.000 & 0.000 \\
\hline Actin with Betanapthaflavone & -9.5 & 0.000 & 0.000
\end{tabular}

Table 5. Energy and RMSD values for HSP with Ligands.

\begin{tabular}{l|c|c|c} 
Protein with ligand & Energy & RMSD.LB & RMSD.UB \\
\hline HSP with Quercetin & -6.7 & 0.000 & 0.000 \\
\hline HSP with Apigenin & -6.5 & 0.000 & 0.000 \\
\hline HSP with chrysin & -6.6 & 0.000 & 0.000 \\
\hline HSP with Hispidulin & -6.4 & 0.000 & 0.000 \\
\hline HSP with Luteolin & -6.6 & 1.580 & 1.633 \\
\hline HSP with Diosmetin & -6.7 & 0.000 & 0.000 \\
\hline HSP with Fisetin & -6.6 & 0.000 & 0.000 \\
\hline HSP with Kaempherol & -6.5 & 0.000 & 0.000 \\
\hline HSP with Flavone & -6.4 & 0.000 & 0.000 \\
\hline HSP with 2-Phenyl-4H-Benzo(H)Chromen-4-One & -7.3 & 0.000 & 0.000 \\
\hline HSP with 5,7-Dihydroxy-2-(3,4,5-TrihydroxyphenylL)-4H-Chromen-4-One & -6.7 & 0.000 & 0.000 \\
\hline HSP with Recoflavone & -6.4 & 0.000 & 0.000 \\
\hline HSP with Icaritin & -7.3 & 0.000 & 0.000 \\
\hline HSP with Betanapthaflavone & -6.9 & 0.000 & 0.000 \\
\hline
\end{tabular}

5, 7, 2-Trihydroxy-6, 8-Dimethoxyflavone of the binding energy of -14.0 have strong interaction with APAF-1 (Fig 1e). Recoflavone compound is said to possess very weak interaction with APAF as its value is higher. From the overall ligand binding result of quercetin and analog with APAF we could conclude that quercetin and its analogs are said to have fewer interactions with APAF protein. In the case of RMSD value, most of the compounds have a value of 0.0 , which is acceptable (table 6).

Table 6. Energy and RMSD values for APAF-1 with other ligands.

Protein with ligand

\begin{tabular}{|c|c|c|c|}
\hline Protein with ligand & Energy & RMSD.LB & RMSD.UB \\
\hline APAF-1 with Quercetin & 3.8 & 0.000 & 0.000 \\
\hline APAF-1 with Apigenin & -3.0 & 0.000 & 0.000 \\
\hline APAF-1 with chrysin & -3.4 & 0.000 & 0.000 \\
\hline APAF-1 with Hispidulin & -1.3 & 0.000 & 0.000 \\
\hline APAF-1 with Luteolin & -0.6 & 0.000 & 0.000 \\
\hline APAF-1 with Diosmetin & 1.3 & 0.000 & 0.000 \\
\hline APAF-1 with Fisetin & -0.9 & 0.000 & 0.000 \\
\hline APAF-1 with Kaempherol & 2.5 & 0.000 & 0.000 \\
\hline APAF-1 with Flavone & -4.1 & 0.000 & 0.000 \\
\hline APAF-1 with 2-Phenyl-4H-Benzo(H)Chromen-4-One & 3.4 & 0.000 & 0.000 \\
\hline APAF-1 with 5,7-Dihydroxy-2-(3,4,5-TrihydroxyphenylL)-4H-Chromen-4-One & 6.2 & 0.000 & 0.000 \\
\hline APAF-1 with 5,7,2-Trihydroxy-6,8-Dimethoxyflavone & -14.0 & 0.000 & 0.000 \\
\hline APAF-1 with Recoflavone & 59.5 & 0.000 & 0.000 \\
\hline APAF-1 with Icaritin & 39.7 & 0.000 & 0.000 \\
\hline APAF-1 with Betanapthaflavone & 1.1 & 1.014 & 2.404 \\
\hline
\end{tabular}

For the BAX protein (Fig 1f), Recoflavone has stronger interaction compared to other analogs. It has a higher binding energy of -8.3 , which is followed by Betanapthaflavone of energy value -8.2. Except for quercetin, all other compounds have good interaction with the target protein. As the value of quercetin is very much higher, it is said to possess weaker 
interaction. All the compounds possess hydrogen bonds, which depicts that they have good interaction (table 7).

Table 7. Energy and RMSD values for BAX with selected ligands.

\begin{tabular}{|c|c|c|c|}
\hline Protein with ligand & Energy & RMSD.LB & RMSD.UB \\
\hline BAX with Quercetin & 3.8 & 0.000 & 0.000 \\
\hline BAX with Apigenin & -7.3 & 0.000 & 0.000 \\
\hline BAX with chrysin & -7.3 & 0.000 & 0.000 \\
\hline BAX with Hispidulin & -7.4 & 0.000 & 0.000 \\
\hline BAX with Luteolin & -7.4 & 0.000 & 0.000 \\
\hline BAX with Diosmetin & -7.1 & 0.000 & 0.000 \\
\hline BAX with Fisetin & -6.9 & 0.000 & 0.000 \\
\hline BAX with Kaempherol & -6.6 & 0.000 & 0.000 \\
\hline BAX with Flavone & -7.1 & 0.000 & 0.000 \\
\hline BAX with 2-Phenyl-4H-Benzo(H)Chromen-4-One & -7.8 & 0.000 & 0.000 \\
\hline BAX with 5,7-Dihydroxy-2-(3,4,5-TrihydroxyphenylL)-4H-Chromen-4-One & -7.3 & 0.000 & 0.000 \\
\hline BAX with 5,7,2-Trihydroxy-6,8-Dimethoxyflavone & -7.0 & 0.000 & 0.000 \\
\hline BAX with Recoflavone & -8.3 & 0.000 & 0.000 \\
\hline BAX with Icaritin & -6.9 & 0.000 & 0.000 \\
\hline BAX with Betanapthaflavone & -8.2 & 0.000 & 0.000 \\
\hline
\end{tabular}

In the case of tyrosine-protein kinase HCK (Fig 1g) and Bcl-2 protein (Fig 1h), Recoflavone have stronger interaction of binding energy -8.0 and a-10.6 respectively (table 8 \& 9), and all other compounds said to possess average interaction with the protein. All other parameters such as RMSD value, aromaticity, and hydrogen bonds are in the good range.
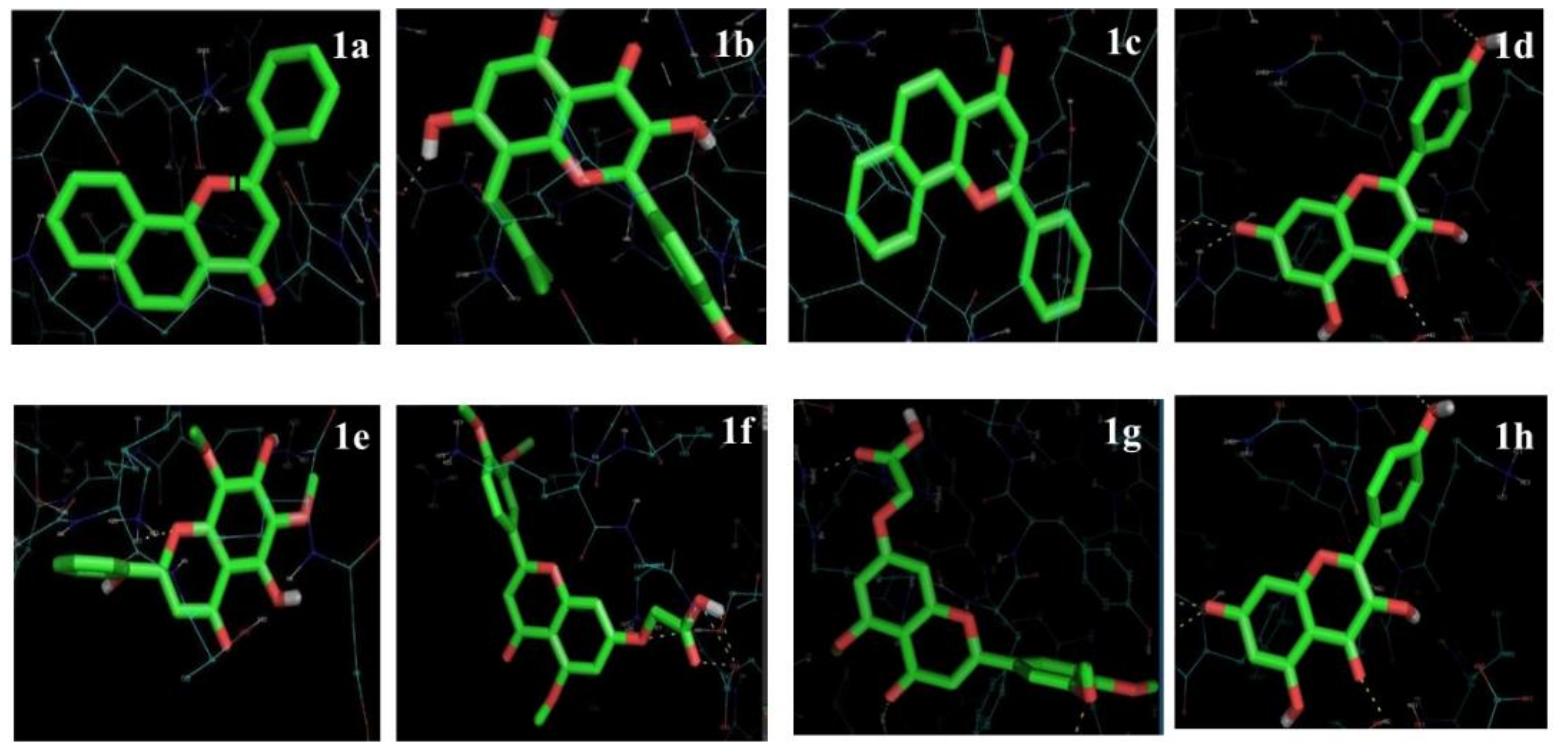

Figure 1. a. Docking results of cytochrome P 450 with 2-Phenyl-4H-Benzo (H) Chromen-4-One; b. Docking results of actin with betanapthaflavone; c. Docking results of HSP with 2-Phenyl-4H-Benzo (H) Chromen-4-One; d. Docking results of HSP with recoflavone; e. Docking results of APAF -1 with 5, 7, 2-Trihydroxy-6, 8Dimethoxyflavone; f. Docking results of BAX with recoflavone; g. Docking results of Tyrosine-protein kinase HCK with recoflavone; h. Docking results of BCL -2 with recoflavone.

Table 8. Energy and RMSD values for Tyrosine-protein kinase HCK with selected ligands.

Protein with ligand

\begin{tabular}{|c|c|c|c|}
\hline & & & \\
\hline Tyrosine Protein Kinase HCK with Quercetin & -8.8 & 0.000 & 0.000 \\
\hline Tyrosine Protein Kinase HCK with Apigenin & -8.8 & 0.000 & 0.000 \\
\hline Tyrosine Protein Kinase HCK with chrysin & -9.1 & 0.000 & 0.000 \\
\hline Tyrosine Protein Kinase HCK with Hispidulin & -8.3 & 0.000 & 0.000 \\
\hline Tyrosine Protein Kinase HCK with Luteolin & -8.8 & 0.6 & 1.507 \\
\hline Tyrosine Protein Kinase HCK with Diosmetin & -8.6 & 0.000 & 0.000 \\
\hline Tyrosine Protein Kinase HCK with Fisetin & -8.6 & 0.000 & 0.000 \\
\hline Tyrosine Protein Kinase HCK with Kaempherol & -8.6 & 0.000 & 0.000 \\
\hline Tyrosine Protein Kinase HCK with Flavone & -8.5 & 0.000 & 0.000 \\
\hline https://biointerfaceresearch.com/ & & & $\overline{13701}$ \\
\hline
\end{tabular}




\begin{tabular}{|c|c|c|c|}
\hline Protein with ligand & Energy & RMSD.LB & RMSD.UB \\
\hline Tyrosine Protein Kinase HCK with 2-Phenyl-4H-Benzo(H)Chromen-4-One & -9.4 & 0.000 & 0.000 \\
\hline $\begin{array}{l}\text { Tyrosine Protein Kinase HCK with 5,7-Dihydroxy-2-(3,4,5-TrihydroxyphenylL)- } \\
\text { 4H-Chromen-4-One }\end{array}$ & -9.0 & 0.000 & 0.000 \\
\hline Tyrosine Protein Kinase HCK with 5,7,2-Trihydroxy-6,8-Dimethoxyflavone & -8.0 & 1.080 & 1.200 \\
\hline Tyrosine Protein Kinase HCK with Recoflavone & -10.6 & 0.000 & 0.000 \\
\hline Tyrosine Protein Kinase HCK with Icaritin & -9.3 & 0.000 & 0.000 \\
\hline Tyrosine Protein Kinase HCK with Betanapthaflavone & -9.0 & 0.000 & 0.000 \\
\hline
\end{tabular}

Table 9. Energy and RMSD values for BCL-2 with ligands.

\begin{tabular}{l|c|c|c} 
Protein with ligand & Energy & RMSD.LB & RMSD.UB \\
\hline BCL-2 with Quercetin & -7.6 & 0.000 & 0.000 \\
\hline BCL-2 with Apigenin & -7.8 & 0.000 & 0.000 \\
\hline BCL-2 with chrysin & -7.9 & 0.000 & 0.000 \\
\hline BCL-2 with Hispidulin & -7.5 & 0.000 & 0.000 \\
\hline BCL-2 with Luteolin & -8.2 & 0.000 & 0.000 \\
\hline BCL-2 with Diosmetin & -8.1 & 0.000 & 0.000 \\
\hline BCL-2 with Fisetin & -7.6 & 0.000 & 0.000 \\
\hline BCL-2 with Kaempherol & -7.6 & 0.000 & 0.000 \\
\hline BCL-2 with Flavone & -7.2 & 0.000 & 0.000 \\
\hline BCL-2 with 2-Phenyl-4H-Benzo(H)Chromen-4-One & -8.1 & 0.000 & 0.000 \\
\hline BCL-2 with 5,7-Dihydroxy-2-(3,4,5-TrihydroxyphenylL)- & -8.2 & 0.000 & 0.000 \\
4H-Chromen-4-One & & & \\
\hline BCL-2 with 5,7,2-Trihydroxy-6,8-Dimethoxyflavone & -7.5 & 0.000 & 0.000 \\
\hline BCL-2 with Recoflavone & -8.4 & 0.000 & 0.000 \\
\hline BCL-2 with Icaritin & -7.2 & 0.000 & 0.000 \\
\hline BCL-2 with Betanapthaflavone & -8.0 & 0.000 & 0.000
\end{tabular}

Based on the docking score Recoflavone have a high score ranking compare to other compounds. The analog Recoflavone is said to possess good interaction with most of the targeted proteins. Based on all the overall summary results, we could conclude that quercetin and analogs can be considered a potent drug for cancer treatment. Referring to the above results, quercetin proves to be efficient and safe. Hence, quercetin can be further developed as a potential drug for breast and ovarian cancer. The advancement in research helps to move forward in the drug discovery pipeline to use quercetin in cancer treatment.

\section{Conclusions}

From the In silico research completed, we can infer that quercetin and the following analogs show great efficacy in finding against cancer and can be used in cancer care. Since quercetin is a natural flavanol that is easily found in onions, flax seeds can help people fight cancer more effectively with dietary nutrients. Many researchers suggest that quercetin in flaxseed effectively combats breast cancer, ovarian cancer, and endometriosis. Quercetin and its analogs can be selected as a lead molecule to develop a drug. It will help the pharmacist and developers produce a successful outcome of a drug and give a triumphant result in Clinical trials.

\section{Funding}

Ministry of Science and Technology, Department of Science and Technology (KIRAN Division) (GoI), New Delhi. (Ref No. DST/WOSB/ 2018/1583-HFN (G).

\section{Acknowledgments}

The authors gratefully acknowledge the Ministry of Science and Technology, Department of Science and Technology (KIRAN Division) (GoI), New Delhi. (Ref No. DST/WOSB/ 
2018/1583-HFN (G)). The authors are also thankful to B.S. Abdur Rahman Institute of Science \& Technology, Chennai, provides research facilities in the School of Life Sciences.

\title{
Conflicts of Interest
}

\author{
The authors declare no conflict of interest.
}

\section{References}

1. Ma, X.; Yu, H. Global burden of cancer. Yale J. Biol. Med, 2006, 79, 85-94.

2. $\quad$ Li, Y.; Feng, X.; Zhang, Y.; Wang, Y.; Yu, X.; Jia, R.; Yu, T.; Zheng, X.; Chu, Q. Dietary flavone from the Tetrastigma hemsleyanum vine triggers human lung adenocarcinoma apoptosis via autophagy. Food \& Function 2020, 11, 9776-9788, https://doi.org/10.1039/d0fo01997f.

3. Parsa, N. Environmental factors inducing human cancers. Iran J Public Health 2012, 41, 1-9.

4. Klebe, S.; Leigh, J.; Henderson, D.W.; Nurminen, M. Asbestos, Smoking and Lung Cancer: An Update. Int J Environ Res Public Health 2019, 17, https://doi.org/10.3390/ijerph17010258.

5. ARC Working Group on the Evaluation of Carcinogenic Risks to Humans. Red Meat and Processed Meat. Lyon (FR): International Agency for Research on Cancer; (IARC Monographs on the Evaluation of Carcinogenic Risks to Humans, No. 114.), 2018.

6. undaram, M.K.; Khan, M.A.; Alalami, U.; Somvanshi, P.; Bhardwaj, T.; Pramodh, S.; Raina, R.; Shekfeh, Z.; Haque, S.; Hussain, A. Phytochemicals induce apoptosis by modulation of nitric oxide signaling pathway in cervical cancer cells. Eur Rev Med Pharmacol Sci 2020, 24, 11827-11844, https://doi.org/10.26355/eurrev_202011_23840.

7. Ozkan, E.; Bakar-Ates, F. Potentiation of the Effect of Lonidamine by Quercetin in MCF-7 human breast cancer cells through downregulation of MMP-2/9 mRNA Expression. Anais da Academia Brasileira de Ciências 2020, 92, https://doi.org/10.1590/0001-3765202020200548.

8. Chen, S.-Q.; Wang, C.; Song, Y.-Q.; Tao, S.; Yu, F.-Y.; Lou, H.-Y.; Hu, F.-Q.; Yuan, H. Quercetin Covalently Linked Lipid Nanoparticles: Multifaceted Killing Effect on Tumor Cells. ACS Omega 2020, 5 , 30274-30281, https://doi.org/10.1021/acsomega.0c04795.

9. Yousuf, M.; Khan, P.; Shamsi, A.; Shahbaaz, M.; Hasan, G.M.; Haque, Q.M.R.; Christoffels, A.; Islam, A.; Hassan, M.I. Inhibiting CDK6 Activity by Quercetin Is an Attractive Strategy for Cancer Therapy. ACS Omega 2020, 5, 27480-27491, https://doi.org/10.1021/acsomega.0c03975.

10. Girardelo, J.R.; Munari, E.L.; Dallorsoleta, J.C.S.; Cechinel, G.; Goetten, A.L.F.; Sales, L.R.; Reginatto, F.H.; Chaves, V.C.; Smaniotto, F.A.; Somacal, S.; Emanuelli, T.; Benech, J.C.; Soldi, C.; Winter, E.; Conterato, G.M.M. Bioactive compounds, antioxidant capacity and antitumoral activity of ethanolic extracts from fruits and seeds of Eugenia involucrata DC. Food Research International 2020, 137, https://doi.org/10.1016/j.foodres.2020.109615.

11. Guo, Y.; Tong, Y.; Zhu, H.; Xiao, Y.; Guo, H.; Shang, L.; Zheng, W.; Ma, S.; Liu, X.; Bai, Y. Quercetin suppresses pancreatic ductal adenocarcinoma progression via inhibition of SHH and TGF- $\beta /$ Smad signaling pathways. Cell Biology and Toxicology 2020, 17, https://doi.org/10.1007/s10565-020-09562-0.

12. Singh, C.K.; Chhabra, G.; Ndiaye, M.A.; Siddiqui, I.A.; Panackal, J.E.; Mintie, C.A.; Ahmad, N. QuercetinResveratrol Combination for Prostate Cancer Management in TRAMP Mice. Cancers 2020, 12, https://doi.org/10.3390/cancers12082141.

13. Panche, A.N.; Diwan, A.D.; Chandra, S.R. Flavonoids: an overview. Journal of Nutritional Science 2016, 5, https://doi.org/10.1017/jns.2016.41.

14. Anand David, A.V.; Arulmoli, R.; Parasuraman, S. Overviews of Biological Importance of Quercetin: A Bioactive Flavonoid. Pharmacognosy reviews 2016, 10, 84-89, https://doi.org/10.4103/0973-7847.194044.

15. Sabando, C.; Rodríguez-Díaz, M.; Ide, W.; Pastene, E.; Avello, M.; Simirgiotis, M.; Rojas, S.; Villarroel, E.; Silva-Grecchi, T.; Gutiérrez, C.; Bouza, R.; Cicchelli, B.; González, M.; Rodríguez-Llamazares, S. Improvement of endothelial function by Gunnera tinctoria extract with antioxidant properties. Biological Research 2020, 53, https://doi.org/10.1186/s40659-020-00322-2.

16. Chen, T.; Zhang, X.; Zhu, G.; Liu, H.; Chen, J.; Wang, Y.; He, X. Quercetin inhibits TNF- $\alpha$ induced HUVECs apoptosis and inflammation via downregulating NF-kB and AP-1 signaling pathway in vitro. Medicine 2020, 99, https://doi.org/10.1097/MD.0000000000022241.

17. Gibellini, L.; Pinti, M.; Nasi, M.; Montagna, J.P.; De Biasi, S.; Roat, E.; Bertoncelli, L.; Cooper, E.L.; Cossarizza, A. Quercetin and Cancer Chemoprevention. Evidence-Based Complementary and Alternative Medicine 2011, 2011, https://doi.org/10.1093/ecam/neq053.

18. Lee, J.; Mitchell, A.E. Pharmacokinetics of Quercetin Absorption from Apples and Onions in Healthy Humans. J Agric Food Chem 2012, 60, 3874-3881, https://doi.org/10.1021/jf3001857.

19. Wang, D.; He, X.; Wang, D.; Peng, P.; Xu, X.; Gao, B.; Zheng, C.; Wang, H.; Jia, H.; Shang, Q.; Sun, Z.; Luo, Z.; Yang, L. Quercetin Suppresses Apoptosis and Attenuates Intervertebral Disc Degeneration via the 
SIRT1-Autophagy Pathway. Frontiers in Cell and Developmental Biology 2020, 8, https://doi.org/10.3389/fcell.2020.613006.

20. Shi, H.; Li, X.-Y.; Chen, Y.; Zhang, X.; Wu, Y.; Wang, Z.-X.; Chen, P.-H.; Dai, H.-Q.; Feng, J.; Chatterjee, S.; Li, Z.-J.; Huang, X.-W.; Wei, H.-Q.; Wang, J.; Lu, G.-D.; Zhou, J. Quercetin Induces Apoptosis via Downregulation of Vascular Endothelial Growth Factor/Akt Signaling Pathway in Acute Myeloid Leukemia Cells. Frontiers in Pharmacology 2020, 11, https://doi.org/10.3389/fphar.2020.534171.

21. Wang, Z.-X.; Ma, J.; Li, X.-Y.; Wu, Y.; Shi, H.; Chen, Y.; Lu, G.; Shen, H.-M.; Lu, G.-D.; Zhou, J. Quercetin induces p53-independent cancer cell death through lysosome activation by the transcription factor EB and Reactive Oxygen Species-dependent ferroptosis. British Journal of Pharmacology 2020, 21, https://doi.org/10.1111/bph.15350.

22. Moujahed S.; Ruiz A.; Hallegue D.; Sakly M. Quercetin alleviates styrene oxide-induced cytotoxicity in cortical neurons in vitro via modulation of oxidative stress and apoptosis. Drug Chem Toxicol 2020, 9, 1-10, https://doi.org/10.1080/01480545.2020.1851706.

23. Vakili, S.; Zal, F.; Mostafavi-pour, Z.; Savardashtaki, A.; Koohpeyma, F. Quercetin and vitamin E alleviate ovariectomy-induced osteoporosis by modulating autophagy and apoptosis in rat bone cells. Journal of Cellular Physiology 2020, 8, https://doi.org/10.1002/jcp.30087.

24. Khushbukhat, K.; Zeeshan, J.; Haleema, S.; Javad, S.-R.; William, C.C.; Claudio, L. Quercetin and MicroRNA Interplay in Apoptosis Regulation in Ovarian Cancer. Current Pharmaceutical Design 2020, 26, 1-9, https://doi.org/10.2174/1381612826666201019102207.

25. Shafabakhsh, R.; Asemi, Z. Quercetin: a natural compound for ovarian cancer treatment. J Ovarian Res 2019, 12, https://doi.org/10.1186/s13048-019-0530-4.

26. Soll, F.; Ternent, C.; Berry, I.M.; Kumari, D.; Moore, T.C. Quercetin Inhibits Proliferation and Induces Apoptosis of B16 Melanoma Cells In Vitro. ASSAY and Drug Development Technologies 2020, 18, 261268, https://doi.org/10.1089/adt.2020.993.

27. Boam, T. Anti-androgenic effects of flavonols in prostate cancer. Ecacnermedicalscience 2015, 9, https://doi.org/10.3332/ecancer.2015.585.

28. Kinker, B.; Comstock, A.T.; Sajjan, U.S. Quercetin: A Promising Treatment for the Common Cold. Journal of Ancient Diseases \& Preventive Remedies 2014, 02, https://doi.org/10.4172/2329-8731.1000111.

29. Zhou, J.; Fang, L.; Liao, J.; Li, L.; Yao, W.; Xiong, Z.; Zhou, X. Investigation of the anti-cancer effect of quercetin on HepG2 cells in vivo. PLOS ONE 2017, 12, https://doi.org/10.1371/journal.pone.0172838.

30. Yardim, A.; Kandemir, F.M.; Ozdemir, S.; Kucukler, S.; Comakli, S.; Gur, C.; Celik, H. Quercetin provides protection against the peripheral nerve damage caused by vincristine in rats by suppressing caspase 3, NFкB, ATF-6 pathways and activating Nrf2, Akt pathways. Neurotoxicology 2020, 81, 137-146, https://doi.org/10.1016/j.neuro.2020.10.001.

31. Tummala, R.; Lou, W.; Gao, A.C.; Nadiminty, N. Quercetin Targets hnRNPA1 to Overcome Enzalutamide Resistance in Prostate Cancer Cells. Molecular Cancer Therapeutics 2017, 16, 2770-2779, https://doi.org/10.1158/1535-7163.MCT-17-0030.

32. Song, J.; Bai, J.; Wang, S.; Liu, L.; Zhao, Z. [Effects of Quercetin on Autophagy and Phosphatidylinositol 3-kinase/Protein Kinase B/Mammalian Target of Rapamycin Signaling Pathway in Human Prostate Cancer PC-3 Cells]. Zhongguo yi xиe ke xие yиan xиe bao. Acta Academiae Medicinae Sinicae 2020, 42, 578-584.

33. Khodabandeh, Z.; Dolati, P.; Zamiri, M.J.; Mehrabani, D.; Bordbar, H.; Alaee, S.; Jamhiri, I.; Azarpira, N. Protective Effect of Quercetin on Testis Structure and Apoptosis Against Lead Acetate Toxicity: an Stereological Study. Biological Trace Element Research 2020, 27, https://doi.org/10.1007/s12011-02002454-8.

34. Guo, Y.; Mah, E.; Davis, C.G.; Jalili, T.; Ferruzzi, M.G.; Chun, O.K.; Bruno, R.S. Dietary fat increases quercetin bioavailability in overweight adults. Molecular Nutrition \& Food Research 2013, 57, 896-905, https://doi.org/10.1002/mnfr.201200619.

35. Begum, S.M.F.M.; Priya, S.; Sundararajan, R.; Hemalatha, S. Novel anticancerous compounds from Sargassum wightii: In silico and in vitro approaches to test the antiproliferative efficacy. J. Adv. Pharm. Educ 2017, 7, 272-7.

36. Begum, S.M.F.; Priya, S.; Hemalatha, S. In vitro and In silico analysis of the Anti oxidant and Angiogenic potential of Padina tetrastomatica. Int. J. Pharmtech Res 2017, 10, 223-30.

37. Priya, S.; Kumar, N.S.; Hemalatha, S. Antiviral phytocompounds target envelop protein to control Zika $\begin{array}{lllll}\text { virus. } \quad \text { Computational } & \text { Biology and }\end{array}$ https://doi.org/10.1016/j.compbiolchem.2018.08.008.

38. Lutfiya, A.S.; Priya, S.; Manzoor, M.A.P.; Hemalatha, S. Molecular docking and interactions between vascular endothelial growth factor (VEGF) receptors and phytochemicals: An in-silico study. Biocatalysis and Agricultural Biotechnology 2019, 22,https://doi.org/10.1016/j.bcab.2019.101424.

39. Arpudhamary, V.; Priya, S.; Manzoor, M.A.P.; Mubarakali, D.; Hemalatha, S. Apoptotic-inducing factor 1 (AIF1) plays a critical role in cembranoid mediated apoptosis to control cancer: Molecular docking and dynamics study. Biocatalysis and Agricultural Biotechnology 2019, 22, https://doi.org/10.1016/j.bcab.2019.101343. 
40. Sabiha Sulthana, H.B.; Ranjani, S.; Hemalatha S. Comparison of efficacy of nanoparticles synthesized from leaves and flowers of Russelia equisitiformis. Inorganic and Nano-Metal Chemistry 2020, https://doi.org/10.1080/24701556.2020.1862218.

41. Sai Nivetha, S.; Ranjani, S.; Hemalatha, S. Synthesis and application of silver nanoparticles using Cissus quadrangularis, Inorg. Nano-Met. Chem 2020. https://doi.org/10.1080/24701556.2020.1862219.

42. Xuan-Yu, M.; Hong-Xing, Z.; Mihaly, M.; Meng, C. Molecular Docking: A Powerful Approach for Structure-Based Drug Discovery. Current Computer-Aided Drug Design 2011, 7, 146-157, https://doi.org/10.2174/157340911795677602.

43. Sliwoski, G.; Kothiwale, S.; Meiler, J.; Lowe, E.W. Computational Methods in Drug Discovery. Pharmacol Rev 2014, 66, 334-395, https://doi.org/10.1124/pr.112.007336.

44. Daina, A.; Michielin, O.; Zoete, V. SwissADME: a free web tool to evaluate pharmacokinetics, drug-likeness and medicinal chemistry friendliness of small molecules. Scientific Reports 2017, 7, https://doi.org/10.1038/srep42717.

45. Hughes, J.P.; Rees, S.; Kalindjian, S.B.; Philpott, K.L. Principles of early drug discovery. British Journal of Pharmacology 2011, 162, 1239-1249, https://doi.org/10.1111/j.1476-5381.2010.01127.x.

46. Rizk, M.L.; Zou, L.; Savic, R.M.; Dooley, K.E. Importance of Drug Pharmacokinetics at the Site of Action. Clinical and Translational Science 2017, 10, 133-142, https://doi.org/10.1111/cts.12448. 